\title{
A PRODUÇÃO ACADÊMICA SOBRE A EDUCAÇÃO DA INFÂNCIA NA BAHIA
} (1970-1990)

\author{
Aline Pimentel Cupertino ${ }^{1}$ Faní Quitéria Nascimento Rehem ${ }^{2}$ \\ 1. Bolsista PIBIC/CNPq, Graduanda em Pedagogia, Universidade Estadual de Feira de Santana, e-mail: \\ alinepimentelcupertino07@gmail.com \\ 2. Orientadora, Departamento de Educação, Universidade Estadual de Feira de Santana, e-mail: fanirehem@uefs.br
}

PALAVRAS-CHAVE: Educação Infantil. História da Bahia. Estado da Arte

\section{INTRODUÇÃO}

A infância é a fase inicial da vida dos seres humanos que se inicia desde o seu nascimento e vai até os 12 anos de idade, segundo o Estatuto da Criança e do Adolescente, Lei 8069/90 de 13 de julho de 1990 (BRASIL, 1990).

A educação é um direito de todos e dever do Estado e da família. A Educação Infantil passou a ser direito da criança, e a creche foi reconhecida, ao lado da pré-escola, como instituição educacional, como parte da Educação Básica a partir de lutas que inseriram essa etapa na Constituição Federal de 1988.

Art. 205. A educação, direito de todos e dever do Estado e da família, será promovida e incentivada com a colaboração da sociedade, visando ao pleno desenvolvimento da pessoa, seu preparo para o exercício da cidadania e sua qualificação para o trabalho.(BRASIL, 1988)

Segundo a Lei de Diretrizes e Bases da Educação Nacional Lei 9394/96 de 20 de dezembro de 1996, a Educação Infantil seria a primeira etapa da Educação Básica:

Art. 29. A educação infantil, primeira etapa da educação básica, tem como finalidade o desenvolvimento integral da criança de até 5 (cinco) anos, em seus aspectos físico, psicológico, intelectual e social, complementando a ação da família e da comunidade.

Fúlvia Rosemberg (2003), pesquisadora consagrada no campo das políticas de educação infantil define que a trajetória da educação infantil está dividida em três períodos, a saber:

a) o primeiro período - final dos anos 1970 e final dos anos 1980 - marcado pelo modelo de baixo custo alinhado ao Unicef e à Unesco e também pela superposição administrativa dos setores de educação, assistência, saúde e trabalho. 
b) segundo período - meados dos anos 1980 a meados dos anos 1990 - fim da Ditadura Militar, caracterizado pela ampla movimentação de organizações sociais e políticas, como grupo de mulheres feministas e grupos de defesa da infância sendo que este último, a partir de intensa mobilização conseguiu garantir o reconhecimento da criança como sujeito de direitos na Constituição Federal de 1988.

c) terceiro período, que culmina com a regulamentação da LDB em 1996, com 8 anos de distância em relação à Constituição Federal de 1988, tempo, segundo a autora, demasiado longo e marcado por transformações nas concepções de Estado e de políticas sociais

Nesse sentido, o presente trabalho objetiva investigar a produção acadêmica que tem o primeiro e o segundo período histórico, definido por Rosemberg (2003), como referência de análise (1970-1990). Assim sendo, o plano de trabalho descrito insere-se no projeto de pesquisa nomeado como "O projeto modernizador e a publicização da educação na Bahia: trajetórias e ações dos sujeitos sociais e das instituições no período 1940-2010" que "tematiza a publicização da educação na Bahia, no período 1940-2010, e procura identificar e qualificar as ações empreendidas por diferentes agentes das políticas públicas para educação e seus desdobramentos para a edificação dos sistemas de educação e a promoção do acesso, permanência e sucesso escolar", justificando a sua relevância, entre outros a ampliação dos conhecimentos sobre a educação na Bahia.

\section{MATERIAL E MÉTODOS OU METODOLOGIA}

Esta pesquisa realizada teve como metodologia o "Estado da arte", também denominado "Estado de conhecimento" que será produzido a partir da análise dos resumos das teses e dissertações. A realização de estudos nesta perspectiva promove um balanço da pesquisa de uma determinada área. Para Romanowski (2006, p. 39) “A realização destes balanços possibilita contribuir com a organização e análise na definição de um campo, uma área, além de indicar possíveis contribuições da pesquisa para com as rupturas sociais".

Realizamos um processo de catalogação de palavras e logo após, fomos em busca dos bancos da CAPES, mas não localizamos as produções, e nos direcionarmos ao banco de dados de universidades em busca destes trabalhos. De início foram selecionadas seis produções, mas somente cinco foram analisadas, pois uma desse total discute educação integral, sem referir-se à educação infantil ou infância.

\section{RESULTADOS E/OU DISCUSSÃO}


Após a identificação do córpus, realizamos a leitura do resumos dos trabalhos selecionados. A partir dos estudos, foi identificado que das cinco produções localizadas, quatro falam sobre educação infantil, apenas duas estão dentro do recorte histórico (1970-1990), uma discutindo sobre a Gestão colegiada da Creche e a outra sobre Educação infantil em Feira de Santana, Sendo o total de cinco Dissertações de Mestrado encontradas e nenhuma tese.

As pesquisas foram encontradas em Universidades localizadas em duas regiões do Brasil Nordeste e Sudeste. Sendo quatro do Nordeste - Universidade Estadual de Feira de Santana (UEFS), Universidade do Estado da Bahia (UNEB), Universidade Estadual do Sudoeste da Bahia (UESB), Universidade Federal da Bahia (UFBA) e apenas uma na Universidade de São Paulo (USP). Outra informação pertinente sobre as produções é que destas encontradas, em sua maioria, são produções de mulheres.

Das cinco produções analisadas, foi possível constatar semelhanças entre as mesmas quanto às suas palavras-chave. Ao todo dois trabalhos possuem palavras em comum, dentre elas estão, Educação Infantil e Políticas Públicas.

O Materialismo Histórico Dialético consta em quatro trabalhos do total encontrado. Nas estratégias de pesquisa utilizaram entrevistas, análise documental. Além disso, o tipo de pesquisa também se repete nas produções sendo quatro de cunho qualitativo. Vale salientar que um dos trabalhos, Santos Jr.(2015), possui tanto abordagem qualitativa como quantitativa.

Sobre a revisão de literatura podemos elucidar que, do total de produções analisadas quatro possuem referencial teórico e apenas uma não apresenta. Além disso, é possível identificar que os autores mais referenciados no trabalhos são: Saviani (1994; 2005,) e Rosemberg (1984; 1992; 1993; 1999; 2002; 2003;) aparecendo em três, do total de trabalhos analisados. Ambos aparecendo juntos em um mesmo trabalho.

É importante destacar que as produções não só referenciam-se em teóricos, mas também se amparam em legislação, a exemplo da Constituição Federal de 1988, a exemplo da Consolidação de Leis Trabalhistas (CLT) e do Estatuto da Criança e do Adolescente (ECA ) e em trabalhos que discorrem sobre a história da educação Infantil e que analisam a creche e as lutas sociais. Outro ponto importante a ser destacado diz respeito às orientadoras das produções. Todas são Doutoras e mulheres, fazendo refletir no quanto o campo da educação é preenchido por mulheres e essas principalmente voltadas à infância. .

Os documentos foram produzidos entre os anos de 2007 a 2019, sendo que duas destas foram desenvolvidas no anos de 2017. Além disso, existem mais produções referentes a temática e período estudado, nos anos de 2015. A porcentagem que representa essa informação chega a 
$40 \%$ dos total analisado. Vale lembrar que os demais anos 2007, 2017 e 2019, atingem apenas $20 \%$ do total de trabalhos.

No decorrer dos estudos realizados foi evidenciado a participação do movimento feminista que é fundamental para tantas conquistas voltadas à criança à infância e seus direitos. Ao discutirem sobre o período dos anos de 1970, os autores trazem informações em comum em relação discussão da mulher necessitar adentrar ao mercado de trabalho e consequentemente necessitar de um lugar para deixar seus filhos.

Os resumos, em sua maioria, aparecem caracterizados como completo ${ }^{1}$, evidenciando com clareza a problemática do estudo, objetivo, estratégia metodologia, base teórica e resultados alcançados. Mas, dois resumos estavam parcialmente completo e nenhum incompleto.

\section{CONSIDERAÇÕES FINAIS}

A partir das análises, é notória a necessidade de produções acerca da infância baiana, pois ainda que tenhamos realizado toda uma catalogação e pesquisa sobre a mesma, ainda foi muito complicado encontrar informações, principalmente dentro do recorte histórico escolhido. A importância da existência de produções sobre a infância baiana para maiores contribuições para novos estudos, possibilitando assim melhorias para a mesma de modo que à medida que se estuda sobre, entende-se mais sobre e assim possibilita-se maiores inovações e melhorias para o campo.

\section{Referências}

BRASIL. [Constituição (1988)]. Constituição da República Federativa do Brasil [recurso eletrônico]. -Brasília : Supremo Tribunal Federal, Secretaria de Documentação, 1988.

. LDB : Lei de diretrizes e bases da educação nacional. - Brasília : Senado Federal, Coordenação de Edições Técnicas, 1996.

ROMANOWSKI, J. P.; ENS, R. T. As pesquisas denominadas do tipo "Estado da Arte" em educação. Diálogos Educacionais, v. 6, n. 6, p. 37-50, 2006.

ROSEMBERG, F. Panorama da Educação Infantil brasileira contemporânea. Anais Simpósio Educação Infantil 2002 / Brasília: UNESCO Brasil, 2003.

KISHIMOTO, Tizuko Morchida. A pré-escola na República. Pro-Posições Nº3 dezembro de 1990

\footnotetext{
1 O presente trabalho define os resumos da seguinte forma: a) Completo (evidencia com clareza problemática de estudo, objetivo, estratégia metodológica, base teórica, resultados alcançados); b) Parcialmente completo (evidencia com clareza no mínimo três critérios relacionados ao resumo completo); c) Insuficiente (não evidencia com clareza a problemática de estudo, objetivo, estratégia metodológica, base teórica, resultados alcançados, o que torna a compreensão do propósito da pesquisa difícil);
} 